\title{
Preparation of Mesoporous Silica-Supported Chiral Amino Alcohols for the Enantioselective Addition of Diethylzinc to Aldehyde and Asymmetric Transfer Hydrogenation to Ketones
}

\author{
Shaheen M. Sarkar, ${ }^{1}$ Md. Eaqub Ali, ${ }^{2}$ Md. Lutfor Rahman, ${ }^{1}$ and Mashitah Mohd Yusoff ${ }^{1}$ \\ ${ }^{1}$ Faculty of Industrial Sciences and Technology, Universiti Malaysia Pahang, 26300 Gambang, Kuantan, Malaysia \\ ${ }^{2}$ Nanotechnology and Catalysis Research Centre (NanoCat), University of Malaya, Level 3, Block A, IPS Building, \\ 50603 Kuala Lumpur, Malaysia
}

Correspondence should be addressed to Md. Eaqub Ali; eaqubali@gmail.com

Received 10 October 2014; Revised 17 December 2014; Accepted 18 December 2014

Academic Editor: Bo Song

Copyright (C) 2015 Shaheen M. Sarkar et al. This is an open access article distributed under the Creative Commons Attribution License, which permits unrestricted use, distribution, and reproduction in any medium, provided the original work is properly cited.

Optically active (-)-ephedrine, (-)-norephedrine, and (-)-prolinol were immobilized onto cubic mesoporous MCM-48 silica. The immobilized amino alcohols served as a heterogeneous chiral catalyst for the asymmetric addition of diethylzinc to aldehydes and transfer hydrogenation to ketones. The developed catalytic process yielded optically enriches secondary aromatic alcohols with 92-99\% conversion and $70-82 \%$ enantioselectivity.

\section{Introduction}

Synthesis of optically active secondary alcohols through the asymmetric addition of organozinc reagent to aldehydes and transfer hydrogenation of ketones is an important chemical process in industry and drugs' synthesis research [1-10]. Reduction of carbonyl group into alcohols involves a number of reducing reagents including addition of alkyl group, molecular hydrogen, metal hydrides, and dissolving metals [11]. The use of the hydrogen donor has some advantages over the use of molecular hydrogen since it avoids risks and constraint associated with hydrogen gas as well as the necessity of pressure controlling vessels and other equipment [12]. In the recent years, covalent immobilization of chiral catalysts onto insoluble supports has attracted much interest [13-17] since it provides an easy separation of products from the catalysts without tedious experimental workup, enabling an efficient recovery of the spent catalyst. It prevents the intermolecular aggregations of the active species because of their rigid structures, which do not swell or dissolve in organic solvents and often exhibit superior thermal and mechanical stability under the catalytic conditions. However, the examples of immobilized catalysts for the asymmetric transfer hydrogenation of ketones have been rare [18, 19]. Further, the immobilization of catalysts onto inorganic supports has been poorly reported [20-22].

The successful development of homogeneous catalysts has sometimes been followed by attempts to attach the catalysts on an insoluble inorganic support [23]. The discovery of ordered mesoporous materials opened a new field for catalyst synthesis. Ordered mesoporous material is one of the attractive inorganic supports in preparing immobilized catalysts. The use of well-defined nanostructured mesoporous materials [24-26], magnetic materials [27], zeolites [28], organic polymers [29], or high surface area carbon [30] for catalytic transformations of organic substrates is an exciting and rapidly growing area. Recently, mesoporous MCM materials with uniform nanosized pore diameters and high specific surface areas have got intense interest as inorganic supports [31-33]. Such immobilization offers practical advantages such as ease of separation and reuse of the catalysts and catalysis within the microenvironment of nanopores. MCM-41 silica has recently been used as a mesoporous support for the immobilization of $\mathrm{Au}, \mathrm{Pt}$, $\mathrm{Pd}, \mathrm{Ni}, \mathrm{Co}$, and $\mathrm{Cu}$ catalysts $[34,35]$. On the other hand, cubic-structured mesoporous MCM-48 silica has received 
less attention due to difficulties in synthesis [36-39]. Owing to its unique three-dimensional pore structure, MCM-48 may be more advantageous than MCM-41. MCM-48 with three-dimensional nanosized pore networks and high specific surface areas would be of high interest in this area. Moreover, organic groups can be robustly anchored to the surface. Attachment of optically active ligands onto the pores of MCM-48 silica can create heterogeneous chiral ligands [40]. Our interest in the field led to prepare MCM-48-supported chiral ligands for asymmetric addition of diethylzinc to aldehydes and asymmetric transfer hydrogenation of ketones. Herein, we describe our results for the asymmetric addition of diethylzinc reagent to aldehydes and transfer hydrogenation to the ketones catalyzed by MCM-48-supported chiral amino alcohol Ru-complex.

\section{Experimental}

2.1. Preparation of the MCM-48 Silica. MCM-48 silica was prepared according to the procedure described in bibliography [39]. The resultant silicate mixture was stirred for $1 \mathrm{~h}$ at room temperature and the samples were then collected by filtration and transferred to a Teflon lined steel vessel. The sample was then heated at $100^{\circ} \mathrm{C}$ for 4 days. After the mixture was cooled, the precipitated product was washed with DI water and calcinated at $500^{\circ} \mathrm{C}$ for $8 \mathrm{~h}$. The MCM-48 was characterized by XRD and TEM analyses.

2.2. Preparation of the Chloropropylated MCM-48 Silica 1 . To a stirred solution of (3-chloropropyl)triethoxysilane (1.2 g, $4.98 \mathrm{mmol})$ in toluene $(25 \mathrm{~mL})$ was added fresh calcinated MCM-48 silica (2.4 g) and the mixture was stirred at $105^{\circ} \mathrm{C}$ for $12 \mathrm{~h}$. The reaction was cooled at room temperature and filtrated. The powder was washed several times with methylene chloride and dried under vacuum at $70^{\circ} \mathrm{C}$ to give 3chloropropylated MCM-48 silica 1 . Weight gain showed that $1.1 \mathrm{mmol}$ of (3-chloropropyl)triethoxysilane was immobilized onto $1.0 \mathrm{~g}$ of mesoporous MCM-48 silica.

2.3. Preparation of the MCM-48-Supported Chiral Amino Alcohols 2. To a stirred solution of $(-)$-ephedrine $(0.23 \mathrm{~g}$, $1.38 \mathrm{mmol})$ and diisopropylethylamine $(0.12 \mathrm{~g}, 0.92 \mathrm{mmol})$ in toluene $(10 \mathrm{~mL})$ was added 3-chloropropylated MCM-48 silica $1(0.7 \mathrm{~g}, 0.77 \mathrm{mmol})$. The mixture was gradually heated at $105^{\circ} \mathrm{C}$ and allowed to react for $36 \mathrm{~h}$. The powder was collected by filtration and successively washed with $\mathrm{H}_{2} \mathrm{O}$, methanol, and $\mathrm{CH}_{2} \mathrm{Cl}_{2}$. The MCM-48-supported ephedrine 2a was obtained after drying in vacuo at $70^{\circ} \mathrm{C}$. Elemental analysis and weight gain showed that $0.47 \mathrm{mmol}$ of ephedrine was anchored onto $1.0 \mathrm{~g}$ of 3-chloropropyl MCM-48 silica 2a. Mesoporous MCM-48-supported norephedrine $\mathbf{2 b}$ and prolinol 2c were obtained by the same procedure with $0.50 \mathrm{mmol} / \mathrm{g}$ and $0.45 \mathrm{mmol} / \mathrm{g}$, respectively.

2.4. General Procedure for the Asymmetric Addition of Diethylzinc to Aldehydes. To a stirred solution of MCM-48 silica $2(5 \mathrm{~mol} \%)$ in hexane $(3 \mathrm{~mL})$ was added $\mathrm{Et}_{2} \mathrm{Zn}(3.0 \mathrm{~mL}$, 1.0 $\mathrm{M}$ in hexane) at $0^{\circ} \mathrm{C}$. The mixture was allowed to reach room temperature and then aldehyde $(1.5 \mathrm{mmol})$ was added to the reaction mixture. The mixture was stirred at room temperature for $10 \mathrm{~h}$ and the reaction progress was observed by TLC analysis. After disappearance of the starting material, the reaction was quenched at $0^{\circ} \mathrm{C}$ by addition of saturated $\mathrm{NH}_{4} \mathrm{Cl}$ solution. The catalyst was removed by filtration and washed with $\mathrm{CH}_{2} \mathrm{Cl}_{2}$. The filtrate was extracted with $\mathrm{CH}_{2} \mathrm{Cl}_{2}$, dried over $\mathrm{Na}_{2} \mathrm{SO}_{4}$, and filtered, and solvent was removed under reduced pressure. The residue was purified by flash chromatography on silica gel with $10 \%$ AcOEt/hexane. The enantiomeric excess was determined by HPLC analysis (Chiralcel OD-H column, 3\% of 2-propanol in hexane, $0.5 \mathrm{~mL} / \mathrm{min}$, and detection at $254 \mathrm{~nm}$ ). Racemic comparison samples were prepared by reactions of the corresponding aldehydes with EtMgBr. Configurations were assigned by comparison with known elution order from a chiral column.

2.5. General Procedure for the Ru-Catalyzed Asymmetric Transfer Hydrogenation to the Ketones with Immobilized Ligand $\mathbf{2 b}$. A suspension was formed by the mixture of $\left[\mathrm{RuCl}_{2}\right.$ ( $p$-cymene $\left.)\right]_{2}(5 \mathrm{mg}, 0.008 \mathrm{mmol})$ and mesoporous silica-supported norephedrine $\mathbf{2 b}(0.016 \mathrm{mmol})$ in 2propanol $(5 \mathrm{~mL})$. The mixture was heated at $80^{\circ} \mathrm{C}$ for $30 \mathrm{~min}$ under nitrogen atmosphere. To this resulting solution, a degassed solution of ketone $(0.83 \mathrm{mmol})$ with $\mathrm{KOH}(2.3 \mathrm{mg}$, $0.04 \mathrm{mmol})$ in 2-propanol $(10 \mathrm{~mL})$ was added and the mixture was stirred at room temperature for $3 \sim 4 \mathrm{~h}$. The reaction was monitored by TLC analysis and after completion of the reaction it was neutralized with aqueous $\mathrm{NH}_{4} \mathrm{Cl}$ solution $(1 \mathrm{~mL})$. The immobilized ligand $\mathbf{2} \mathbf{b}$ was filtrated on a glass filter and washed with water and ethyl acetate. The obtained ligand was dried and used for the next reaction. The excess 2-propanol was removed under reduced pressure and diluted with water and ethyl acetate. The organic layer was washed with brine and dried over $\mathrm{MgSO}_{4}$ and the crude product was purified by short-column chromatography (hexane-ethyl acetate 95/5 as eluent). Enantiomeric excess of the product was determined by HPLC analysis using Chiralcel OD-H column (3\% of 2-propanol in hexane, $1 \mathrm{~mL} / \mathrm{min}$ ).

\section{Results and Discussion}

3.1. Preparation and Characterization of the MCM-48-Supported Chiral Amino Alcohols 2. Soai and coworkers have reported asymmetric addition of diethylzinc reagent to aldehyde catalyzed by silica gel-supported ephedrine [41]. The immobilization of optically active (-)-ephedrine, (-)norephedrine, and (-)-prolinol onto MCM-48 silica was easily performed through two steps as shown in Scheme 1. Treatment of MCM-48 silica with (3-chloropropyl)trimethoxysilane in refluxing toluene gave chloropropylated MCM-48 silica 1 with maximum loading of chloropropyl group $\left(1.1 \mathrm{mmol} / \mathrm{g}\left(\mathrm{CH}_{2}\right)_{3} \mathrm{Cl} / \mathrm{g}\right)$. Reaction of the modified MCM-48 silica 1 with an excess of (-)-ephedrine, (-)norephedrine, and (-)-prolinol in refluxing toluene under basic condition afforded MCM-48-supported ephedrine 2a $(0.47 \mathrm{mmol} / \mathrm{g}), 2 \mathbf{b}(0.50 \mathrm{mmol} / \mathrm{g})$, and 2 c $(0.45 \mathrm{mmol} / \mathrm{g})$, respectively. 


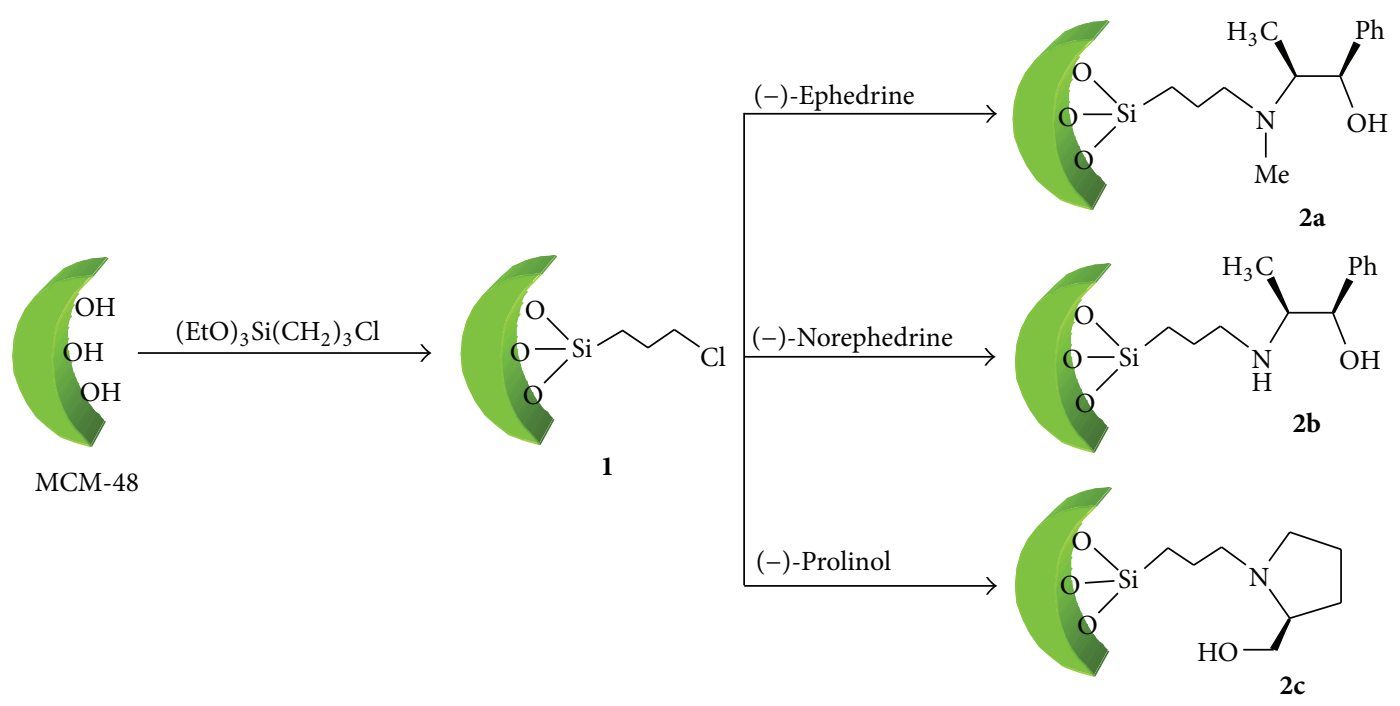

SCHeme 1: Preparation of the MCM-48-supported chiral amino alcohols 2.

TABLE 1: Structural characteristics of MCM-48-supported chiral amino alcohols 2.

\begin{tabular}{lcccc}
\hline Sample & $\begin{array}{c}\text { Surface } \\
\text { area }\end{array}$ & $\begin{array}{c}\text { Pore } \\
\text { diameter }\end{array}$ & $\begin{array}{c}\text { Pore } \\
\text { volume }\end{array}$ & $\begin{array}{c}\text { Loading } \\
\text { amount }\end{array}$ \\
\hline MCM-48 & $1250 \mathrm{~m}^{2} / \mathrm{g}$ & $3.15 \mathrm{~nm}$ & $0.71 \mathrm{~cm}^{3} / \mathrm{g}$ & - \\
2a & $758 \mathrm{~m}^{2} / \mathrm{g}$ & $2.65 \mathrm{~nm}$ & $0.50 \mathrm{~cm}^{3} / \mathrm{g}$ & $0.47 \mathrm{mmol} / \mathrm{g}$ \\
2b & $767 \mathrm{~m}^{2} / \mathrm{g}$ & $2.72 \mathrm{~nm}$ & $0.54 \mathrm{~cm}^{3} / \mathrm{g}$ & $0.50 \mathrm{mmol} / \mathrm{g}$ \\
2c & $794 \mathrm{~m}^{2} / \mathrm{g}$ & $3.11 \mathrm{~nm}$ & $0.61 \mathrm{~cm}^{3} / \mathrm{g}$ & $0.45 \mathrm{mmol} / \mathrm{g}$ \\
\hline
\end{tabular}

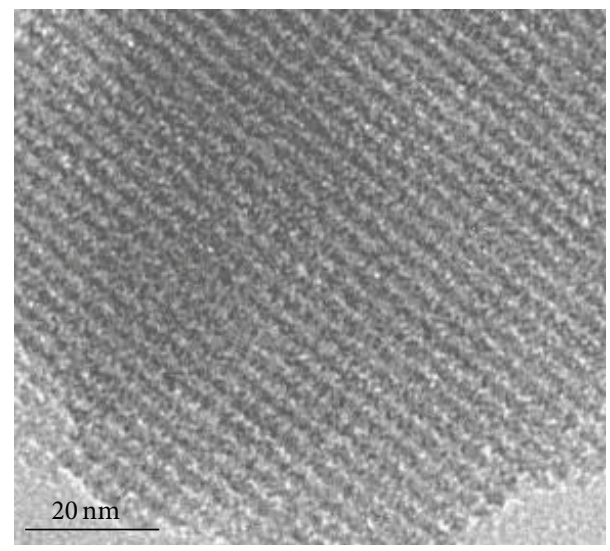

FIGURE 1: TEM image of MCM-48-supported amino alcohol 2a.

The degrees of functionalization were determined by weight gain or elemental analysis. Some physical properties of the modified MCM-48 are summarized in Table 1. The data showed that the functionalized MCM- 48 possesses characteristic pore structure of mesoporous material containing high specific surface area and high mesoporous volume. Surface area and pore diameter of MCM- 482 decreased due to the grafting of organic functional group. HRTEM image was obtained after the modification of the parent MCM- 48

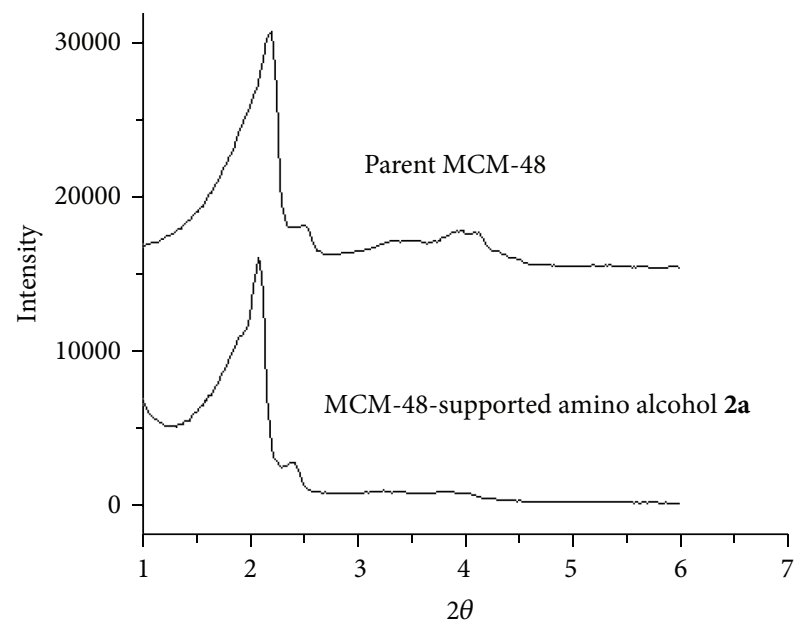

FIGURE 2: XRD pattern of MCM-48-supported amino alcohol 2a.

silica shown in Figure 1. The 3D cubic structure and the pore arrays are conserved after the anchoring of chiral ligand onto MCM-48 silica, which is also confirmed by XRD in Figure 2. Apparently, there is no change of the lattice parameters upon the functionalization process.

3.2. Catalytic Enantioselective Addition of Diethylzinc to the Aldehyde. With the MCM-48-supported chiral amino alcohols 2 in hand, we examined their catalytic efficiency in the addition of diethylzinc to aldehydes in hexane. As shown in Table 2, satisfactory enantioselectivities and high yields were obtained in the presence of MCM-48-supported ephedrine 2a. The results are compared with those obtained using previously reported silica gel-supported ephedrine (entries 5 and 7) [42]. MCM-48-supported ephedrine 2 a gave much higher reaction rate and better asymmetric induction than 
TABLE 2: Asymmetric addition of diethylzinc to aldehydes in the presence of $\mathbf{2}^{\mathrm{a}}$.

\begin{tabular}{|c|c|c|c|c|}
\hline & & $2(5 \mathrm{~mol} \%)$ & & \\
\hline & $\mathrm{ArCHO}+\mathrm{E}$ & hexane & $\operatorname{Ar} R$ & \\
\hline Entry & $\mathrm{Ar}$ & Ligand 2 & Yield $(\%)^{\mathrm{b}}$ & e.e. $(\%)^{\mathrm{c}}$ \\
\hline 1 & $\mathrm{Ph}$ & $2 a$ & 86 & 50 \\
\hline $2^{d}$ & $\mathrm{Ph}$ & $2 a$ & 88 & 52 \\
\hline 3 & $\mathrm{Ph}$ & $2 b$ & 75 & 7 \\
\hline 4 & $\mathrm{Ph}$ & $2 c$ & 80 & 6 \\
\hline $5^{\mathrm{e}}$ & $\mathrm{Ph}$ & $\begin{array}{c}\text { Silica } \\
\text { gel-supported } \\
\mathbf{2 a}\end{array}$ & 59 & 25 \\
\hline 6 & $o-\mathrm{MeOC}_{6} \mathrm{H}_{4}$ & $2 a$ & $90(86)^{\mathrm{f}}$ & $57(54)^{\mathrm{f}}$ \\
\hline $7^{e}$ & $o-\mathrm{MeOC}_{6} \mathrm{H}_{4}$ & $\begin{array}{c}\text { Silica } \\
\text { gel-supported } \\
\mathbf{2 a}\end{array}$ & 65 & 34 \\
\hline 8 & $p-\mathrm{MeC}_{6} \mathrm{H}_{4}$ & $2 a$ & 82 & 43 \\
\hline 9 & $p-\mathrm{ClC}_{6} \mathrm{H}_{4}$ & $2 a$ & 90 & 50 \\
\hline
\end{tabular}

${ }^{a}$ Reactions were carried out in hexane at room temperature using 2 equiv. of $\mathrm{Et}_{2} \mathrm{Zn}$ unless otherwise noted. Absolute configuration was assigned by the elution order from chiral column. ${ }^{\mathrm{b}}$ Determined by GC analysis. ${ }^{\mathrm{c}}$ Determined by HPLC analysis using Chiralcel OD-H column (3\% of 2-propanol in hexane, $0.5 \mathrm{~mL} / \mathrm{min}) .{ }^{\mathrm{d}} 10 \mathrm{~mol} \%$ of ligand was used. ${ }^{\mathrm{e}}$ See [41]. ${ }^{\mathrm{f}}$ The catalyst was reused three times.

TABle 3: Asymmetric transfer hydrogenation of ketones using immobilized ligands $2 \mathbf{b}^{\mathrm{a}}$.

\begin{tabular}{lcccc}
\hline & & & \\
\hline
\end{tabular}

${ }^{\mathrm{a}}$ The reactions were carried out at room temperature in 2-propanol; ketone $: \mathrm{Ru}:$ ligand $: \mathrm{KOH}=100: 1: 2: 5 .{ }^{\mathrm{b}} \mathrm{Acp}=$ acetophenone and $\mathrm{Pp}=$ propiophenone. ${ }^{\mathrm{c}}$ Determined by GC analysis. ${ }^{\mathrm{d}}$ Determined by HPLC analysis using Chiralcel OD-H column (3\% of 2-propanol in hexane, $1 \mathrm{~mL} / \mathrm{min}$ ). ${ }^{\mathrm{e}}$ The catalyst was reused two times. ${ }^{\mathrm{f}}\left[\mathrm{RuCl}_{2} \text { (hexamethylbenzene) }\right]_{2}$ was used instead of $\left[\mathrm{RuCl}_{2}(p \text {-cymene })\right]_{2}$.

silica gel-supported ephedrine 2a. In the case of benzaldehyde, the enantioselectivity was greatly increased from $25 \%$ to $52 \%$ by the use of MCM-48 support (entry 2 versus 5 ). The improved outcome of the reaction seems to be attributed to crystalline structure of MCM-48 support. The MCM- 48 framework allows an ordered array of chiral catalytic sites on the pore surface. The ordered array leads to elegant siteisolation, which may result in enhanced enantioselectivity. It is also noteworthy that our results are comparable to those of the homogeneous system using $\mathrm{N}$-alkyl ephedrine [42]. Next, we did a recycling experiment using chiral ligand $\mathbf{2 a}$. We successfully recovered the catalyst and reused it twice without further addition of Ru-complex (entry 6). However, poor enantioselectivity was observed when the reaction was performed with MCM-48-supported ligands $\mathbf{2 b}$ and $\mathbf{c}$ (entries 3 and 4).

3.3. Catalytic Asymmetric Transfer Hydrogenation of Ketones. Next, the efficiency of MCM-48-supported norephedrine 2b was assessed in ruthenium-catalyzed asymmetric transfer hydrogenation of ketones. The chiral ruthenium catalyst was generated in situ by mixing $\left[\mathrm{Ru}\left(\eta^{6} \text {-arene }\right) \mathrm{Cl}_{2}\right]_{2}$ and supported ligand $\mathbf{2 b}(\mathrm{Ru}$ : ligand $=1: 2)$ in 2-propanol at $80^{\circ} \mathrm{C}$ for $30 \mathrm{~min}$. The catalyst afforded $(R)$-secondary alcohols in up to $82 \%$ enantiomeric excess with $99 \%$ conversion. The reaction conditions and results are summarized in Table 3. $\left[\mathrm{Ru} \text { (hexamethylbenzene) } \mathrm{Cl}_{2}\right]_{2}$ as a $\mathrm{Ru}(\mathrm{II})$ source gave somewhat higher enantiomeric excess than $\left[\mathrm{Ru}(p \text {-cymene }) \mathrm{Cl}_{2}\right]_{2}$. It should be noted that MCM-48-supported ligand $\mathbf{2 b}$ could serve as an effective enantioselective chiral ligand [43].

\section{Conclusions}

The study successfully showed that mesoporous MCM-48 silica can be used as a potential inorganic support for the synthesis of heterogeneous catalysts for the asymmetric addition of diethylzinc reagent to aldehydes and asymmetric transfer hydrogenation of ketones. Promising results were obtained with MCM-48-supported ephedrine, in which ordered structure of MCM-48 had a positive effect on the conversation (99\%) enantioselectivity (82\%). The synthesis of other MCM48-supported chiral ligands for the asymmetric catalysis is underway in our laboratory.

\section{Conflict of Interests}

All authors declare that they have agreed to publish this paper and that it does not have any contents with conflict of interests.

\section{Acknowledgments}

This work was supported by the University of Malaya Fund no. RP005A-2013AET to Md. E. Ali and the University of Malaysia Pahang Fund no. RDU-140124 to S. M. Sarkar.

\section{References}

[1] R. Noyori and M. Kitamura, "Enantioselective addition of organometallic reagents to carbonyl compounds: chirality transfer, multiplication, and amplification," Angewandte Chemie, vol. 30, no. 1, pp. 49-69, 1991.

[2] K. Soai and S. Niwa, "Enantioselective addition of organozinc reagents to aldehydes," Chemical Reviews, vol. 92, no. 5, pp. 833856, 1992. 
[3] L. Pu and H. B. Yu, "Catalytic asymmetric organozinc additions to carbonyl compounds," Chemical Reviews, vol. 101, no. 3, pp. 757-824, 2001.

[4] M. J. Jin, M. S. Sarkar, V. B. Takale, and S. E. Park, "Mesoporous silica SBA-15-supported norephedrine and ephedrine as heterogeneous chiral ligands," Bulletin of the Korean Chemical Society, vol. 26, no. 11, pp. 1671-1672, 2005.

[5] M. S. Sarkar, J.-Y. Jung, and M.-J. Jin, "Asymmetric dihydroxylation catalyzed by SBA15 silica-supported bis-cinchona alkaloid," Studies in Surface Science and Catalysis, vol. 165, pp. 705-708, 2007.

[6] M. A. N. Virboul and R. J. M. K. Gebbink, "Incorporation of an $n$-butylsulfonate functionality to induce aqueous solubility on ruthenium(II) $\eta^{6}$-arene complexes," Organometallics, vol. 31, no. 1, pp. 85-91, 2012.

[7] K. Nomura, K. Tanaka, and S. Fujita, "Use of pyridine-coated star-shaped ROMP polymer as the supporting ligand for ruthenium-catalyzed chemoselective hydrogen transfer reduction of ketones," Organometallics, vol. 31, no. 14, pp. 5074-5080, 2012.

[8] L. Wang, Q. Yang, H. Chen, and R.-X. Li, "A novel cationic dinuclear ruthenium complex: synthesis, characterization and catalytic activity in the transfer hydrogenation of ketones," Inorganic Chemistry Communications, vol. 14, no. 12, pp. 18841888, 2011.

[9] K. Rafikova, N. Kystaubayeva, M. Aydemir et al., "Transfer hydrogenation of ketones catalyzed by new rhodium and iridium complexes of aminophosphine containing cyclohexyl moiety and photosensing behaviors of rhodium and iridium based devices," Journal of Organometallic Chemistry, vol. 758, pp. 1-8, 2014.

[10] A. Kilic, M. Aydemir, M. Durgun et al., "Fluorine/phenyl chelated boron complexes: synthesis, fluorescence properties and catalyst for transfer hydrogenation of aromatic ketones," Journal of Fluorine Chemistry, vol. 162, pp. 9-16, 2014.

[11] F. Alonso, P. Riente, and M. Yus, "Nickel nanoparticles in hydrogen transfer reactions," Accounts of Chemical Research, vol. 44, no. 5, pp. 379-391, 2011.

[12] O. Pàmies and J. E. Bäckvall, "Studies on the mechanism of metal-catalyzed hydrogen transfer from alcohols to ketones," Chemistry, vol. 7, no. 23, pp. 5052-5058, 2001.

[13] N. L. Pei, M. G. Pei, W. Fei, and Q. T. Yong, "Efficient heterogeneous asymmetric transfer hydrogenation of ketones using highly recyclable and accessible silica-immobilized $\mathrm{Ru}-$ TsDPEN catalysts," Organic Letters, vol. 6, no. 2, pp. 169-172, 2004.

[14] D. E. Bergbreiter, "Using soluble polymers to recover catalysts and ligands," Chemical Reviews, vol. 102, no. 10, pp. 3345-3384, 2002.

[15] T. J. Dickerson, N. N. Reed, and K. D. Janda, "Soluble polymers as scaffolds for recoverable catalysts and reagents," Chemical Reviews, vol. 102, no. 10, pp. 3325-3344, 2002.

[16] C. E. Song and S.-G. Lee, "Supported chiral catalysts on inorganic materials," Chemical Reviews, vol. 102, no. 10, pp. 3495-3524, 2002.

[17] Q. H. Fan, Y. M. Li, and A. S. Chan, "Recoverable catalysts for asymmetric organic synthesis," Chemical Reviews, vol. 102, no. 10, pp. 3385-3466, 2002.

[18] A. Rolland, D. Hérault, F. Touchard, C. Saluzzo, R. Duval, and M. Lemaire, "Enantiopure poly(glycidyl methacrylate-coethylene glycol dimethacrylate): a new material for supported catalytic asymmetric hydrogen transfer reduction," Tetrahedron Asymmetry, vol. 12, no. 5, pp. 811-815, 2001.

[19] P. N. Liu, Y. C. Chen, X. Q. Li, Y. Q. Tu, and J. G. Deng, "Dendritic catalysts for asymmetric transfer hydrogenation based $(1 S, 2 R)$-norephedrine derived ligands," Tetrahedron Asymmetry, vol. 14, no. 16, pp. 2481-2485, 2003.

[20] A. Adima, J. J. E. Moreau, and M. W. Chi Man, "Immobilization of rhodium complexes in chiral organic-inorganic hybrid materials," Chirality, vol. 12, no. 5-6, pp. 411-420, 2000.

[21] P. Hesemann and J. J. E. Moreau, "Novel silica-based hybrid materials incorporating binaphthyl units: a chiral matrix effect in heterogeneous asymmetric catalysis," Tetrahedron Asymmetry, vol. 11, no. 10, pp. 2183-2194, 2000.

[22] A. J. Sandee, D. G. I. Petra, J. N. H. Reek, P. C. J. Kamer, and P. W. N. M. van Leeuwen, "Solid-phase synthesis of homogeneous ruthenium catalysts on silica for the continuous asymmetric transfer hydrogenation reaction," Chemistry, vol. 7, no. 6, pp. 1202-1208, 2001.

[23] D. E. de Vos, M. Dams, B. F. Sels, and P. A. Jacobs, "Ordered mesoporous and microporous molecular sieves functionalized with transition metal complexes as catalysts for selective organic transformations," Chemical Reviews, vol. 102, no. 10, pp. 36153640, 2002.

[24] A. P. Wight and M. E. Davis, "Design and preparation of organic-inorganic hybrid catalysts," Chemical Reviews, vol. 102, no. 10, pp. 3589-3614, 2002.

[25] S. Minakata and M. Komatsu, "Organic reactions on silica in water," Chemical Reviews, vol. 109, no. 2, pp. 711-724, 2008.

[26] C. Li, "Chiral synthesis on catalysts immobilized in microporous and mesoporous materials," Catalysis Reviews: Science and Engineering, vol. 46, no. 3-4, pp. 419-492, 2004.

[27] S. Shylesh, V. Schünemann, and W. R. Thiel, "Magnetically separable nanocatalysts: bridges between homogeneous and heterogeneous catalysis," Angewandte Chemie-International Edition, vol. 49, no. 20, pp. 3428-3459, 2010.

[28] T. Maschmeyer, F. Rey, G. Sankar, and J. M. Thomas, "Heterogeneous catalysts obtained by grafting metallocene complexes onto mesoporous silica," Nature, vol. 378, no. 6554, pp. 159-162, 1995.

[29] J. Lu and P. H. Toy, "Organic polymer supports for synthesis and for reagent and catalyst immobilization," Chemical Reviews, vol. 109, no. 2, pp. 815-838, 2009.

[30] S. C. Petrosius, R. S. Drago, V. Young, and G. C. Grunewald, "Low-temperature decomposition of some halogenated hydrocarbons using metal oxide/porous carbon catalysts," Journal of the American Chemical Society, vol. 115, no. 14, pp. 6131-6137, 1993.

[31] K. Mukhopadhyay, B. R. Sarkar, and R. V. Chaudhari, "Anchored Pd complex in MCM-41 and MCM-48: novel heterogeneous catalysts for hydrocarboxylation of aryl olefins and alcohols," Journal of the American Chemical Society, vol. 124, no. 33, pp. 9692-9693, 2002.

[32] W. A. Carvalho, M. Wallau, and U. Schuchardt, "Iron and copper immobilised on mesoporous MCM-41 molecular sieves as catalysts for the oxidation of cyclohexane," Journal of Molecular Catalysis A: Chemical, vol. 144, no. 1, pp. 91-99, 1999.

[33] C. H. Liu and W. Y. Yu, "Ruthenium meso-tetrakis(2,6dichlorophenyl)porphyrin complex immobilized in mesoporous MCM-41 as a heterogeneous catalyst for selective alkene epoxidations," The Journal of Organic Chemistry, vol. 63, no. 21, pp. 7364-7369, 1998. 
[34] M. S. Sarkar, H. Qiu, and M. J. Jin, "Encapsulation of Pd complex in ionic liquid on highly ordered mesoporous silica MCM-41," Journal of Nanoscience and Nanotechnology, vol. 7, no. 11, pp. 3880-3883, 2007.

[35] M. N. Alam and S. M. Sarkar, "Mesoporous MCM-41 supported $N$-heterocyclic carbene-Pd(II) complex for Suzuki coupling reaction," Reaction Kinetics, Mechanisms and Catalysis, vol. 103, no. 2, pp. 493-500, 2011.

[36] D.-H. Park, N. Nishiyama, Y. Egashira, and K. Ueyama, "Enhancement of hydrothermal stability and hydrophobicity of a silica MCM-48 membrane by silylation," Industrial and Engineering Chemistry Research, vol. 40, no. 26, pp. 6105-6110, 2001.

[37] M. Kruk and M. Jaroniec, "Accurate method for calculating mesopore size distributions from argon adsorption data at $87 \mathrm{~K}$ developed using model MCM-41 materials," Chemistry of Materials, vol. 12, no. 1, pp. 222-230, 2000.

[38] J. M. Kim, S. K. Kim, and R. Ryoo, "Synthesis of MCM-48 single crystals," Chemical Communications, no. 2, pp. 259-260, 1998.

[39] K. W. Gallis and C. C. Landry, "Synthesis of MCM-48 by a phase transformation process," Chemistry of Materials, vol. 9, no. 10, pp. 2035-2038, 1997.

[40] M. Heitbaum, F. Glorius, and I. Escher, "Asymmetric heterogeneous catalysis," Angewandte Chemie-International Edition, vol. 45, no. 29, pp. 4732-4762, 2006.

[41] K. Soai, M. Watanabe, and A. Yamamoto, "Enantioselective addition of dialkylzincs to aldehydes using heterogeneous chiral catalysts immobilized on alumina and silica gel," Journal of Organic Chemistry, vol. 55, no. 16, pp. 4832-4835, 1990.

[42] K. Soai, S. Yokoyama, and T. Hayasaka, "Chiral N,Ndialkylnorephedrines as catalysts of the highly enantioselective addition of dialkylzincs to aliphatic and aromatic aldehydes. The asymmetric synthesis of secondary aliphatic and aromatic alcohols of high optical purity," The Journal of Organic Chemistry, vol. 56, no. 13, pp. 4264-4268, 1991.

[43] J. Takehara, S. Hashiguchi, A. Fujii, S. I. Inoue, T. Ikariya, and R. Noyori, "Amino alcohol effects on the ruthenium(II)-catalysed asymmetric transfer hydrogenation of ketones in propan-2-ol," Chemical Communications, no. 2, pp. 233-234, 1996. 

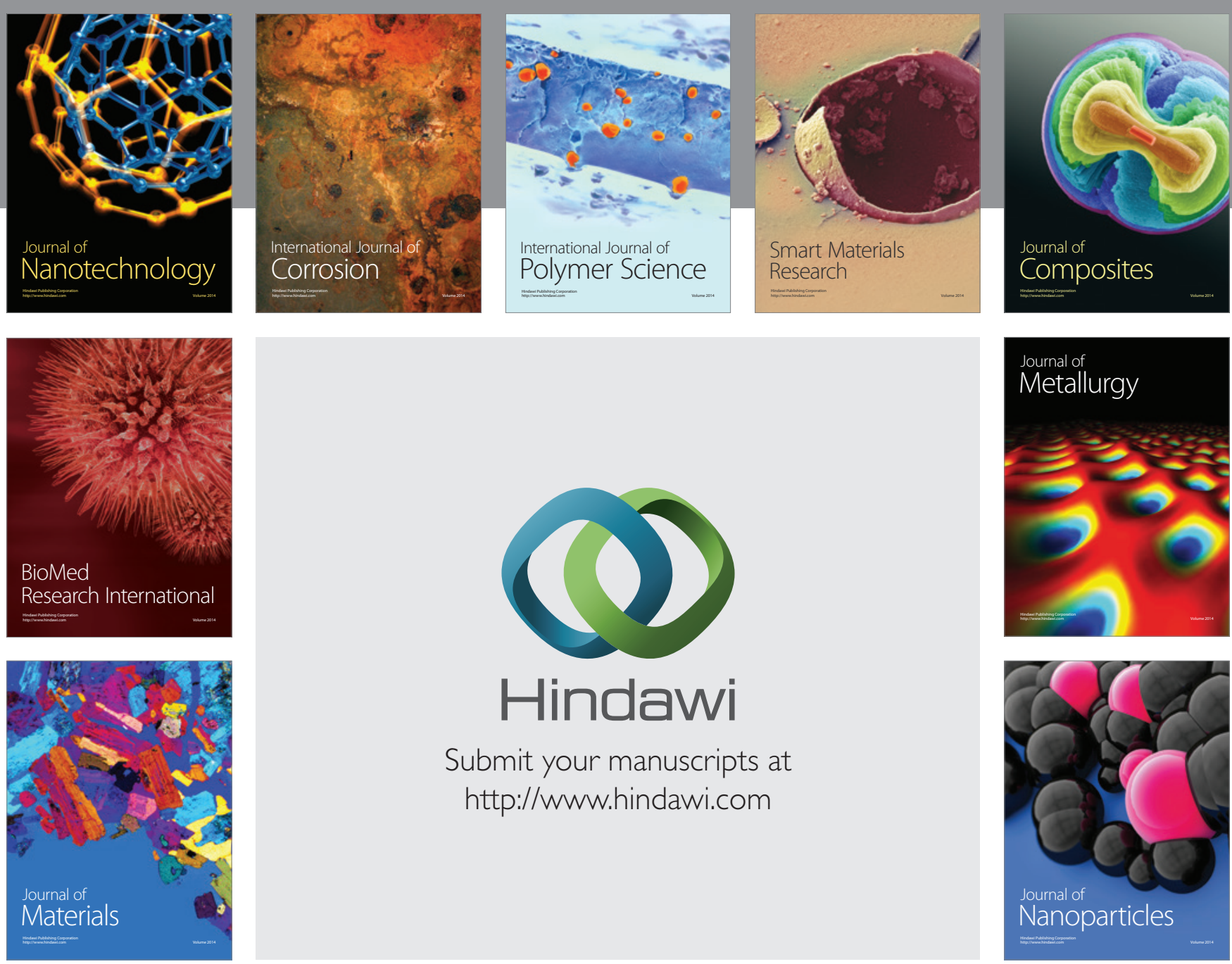

Submit your manuscripts at http://www.hindawi.com
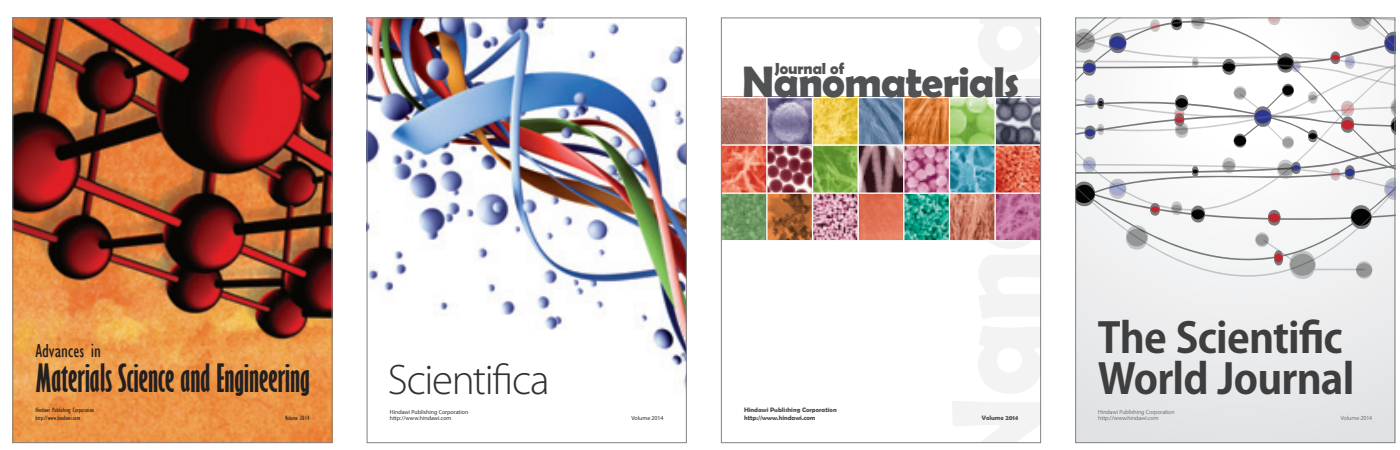

\section{The Scientific World Journal}
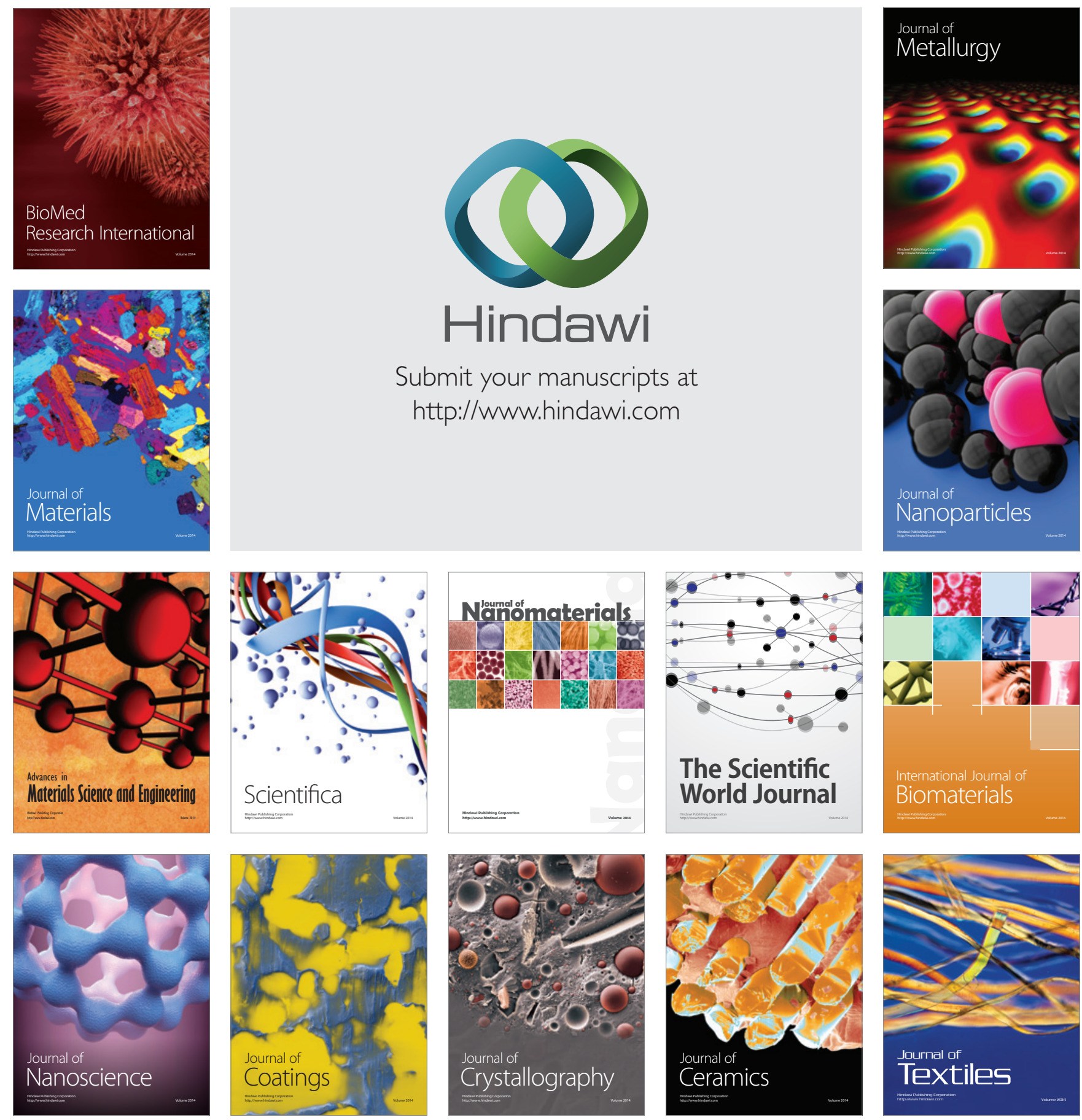